\title{
Creating Accompaniment to a Melody by Using Computer Technologies
}

\author{
Jean Stefanov Pehlivanov \\ Musical Pedagogy Faculty, Academy of Music, Dance and Fine Arts - Plovdiv, Bulgaria
}

Email address:

intro@mail.bg

To cite this article:

Jean Stefanov Pehlivanov. Creating Accompaniment to a Melody by Using Computer Technologies. International Journal of Literature and Arts. Special Issue: Musical Theory, Psychology, Pedagogy and Performing. Vol. 3, No. 5-1, 2015, pp. 50-54.

doi: $10.11648 /$ j.ijla.s.2015030501.17

\begin{abstract}
New electronic technology is featured more and more in the general school. The usage of audio-visual means and computer technologies is becoming an integral part of the classes in Music. The singing activity is fundamental in the music lesson and in the out of class forms of education. For it to be efficient and loved by the students, the role of musical accompaniment is of great importance. The creation of the accompaniment with the help of a synthesizer is an important task of the musical pedagogue.
\end{abstract}

Keywords: Audio-Visual Means, Computer Technologies, Singing Activity, Synthesizer, Musical Accompaniment

\section{Introduction}

We seek the usage of innovations in a close integration of education with science and the technical process. In the modern school, the audio-visual means and the computer technologies are an indispensable prerequisite. One of the many pedagogical methods for the application of computer technologies in musical classes is the creation of musical accompaniment for the performed repertoire of songs. Vocal performance is a main musical activity and the role of the accompaniment is especially important for building the musical image. Singing with accompaniment brings immediate joy and emotion for the students. The musical pedagogue has to develop his/hers abilities to create, with the help of a synthesizer, an appropriate accompaniment, in accordance with the genre and the character of the music.

\section{Subject, Goals and Tasks of the Study}

1. The subject of the present publication is the work of the musical pedagogue in the general school for the creation of an accompaniment to a melody by using a synthesizer.

2. Goal: The present publication is directed towards teachers in music in the general school, helping them acquire practical guidelines for the creation of accompaniment to a melody by using a synthesizer. The ability of the pedagogue to create a good accompaniment will make the song more attractive and engaging, it will increase the active participation of the students in the singing activity.

3. In relation to that goal, the following tasks are set:

$=$ To underline the importance of audio-visual means and computer technologies in the music class.

$=$ To identify the parameters of the singing activity.

$=$ For the musical pedagogue to receive practical guidelines for the creation of an accompaniment to a melody by using the computer and the synthesizer.

\section{The Need for Implementing New Technologies in the Contemporary Musical Education in the General School}

The modern changes in the economical and cultural life, the prompt development of science and the technological progress require new strategies concerning the renovation of the pedagogical activity. The intensively undergoing process in the area of education lead to the usage of new approaches and methods of teaching. The development of electronics, of the new audio recording and audio reproducing technologies creates new opportunities for communication. Electronic products are constantly improving : video, computers, 
compact discs, satellite communications, multimedia productions, etc. The worldwide web marches on and transform the life of people, spreading to all aspects of everyday life, knowledge and the spiritual life. New paths are unveiled for obtaining the most varied information, in particular, musical information: listening to music, creation of music, compressing.

The new electronic technology is entering more and more visibly into schools, in order to increase the effectiveness of the learning process and to make musical lessons interesting, favored and anticipated.

The usage of audio-visual means in education helps connect the visual and audio perceptions for the formation and consolidation of the corresponding notions. The inclusion of more senses in the process of the lesson provides greater accuracy and extensiveness of the knowledge of the students. Through the usage of audio-visual means in front of the students, problematic educative tasks can be presented with the purpose of developing more intensive creative thinking. The audio-visual means as photos, video films, radio and television shows, the usage of a camera, microphone, cassette recorder and all known until now audio sources, are combined as one in the computer and its peripherals. The computer presents vast opportunities for enhancement, variegation and, above all, optimization of the musical education and training.

The new computer technologies constantly expand their application in all areas of the modern life. One of the bright examples in that aspect is the multimedia, which combines in one whole the different audio-visual information carriers. The development of modern technologies led to the creation of such branches of science as computer-aided design, computer graphics and animation, computer-generated music, video games, training programs, simulators of complex physics process.

In musical classes in schools, the computer helps the pedagogue in the performance of various activities: vocal and instrumental performance, perception and composition of music, note literacy, realization of musical means of expression. In this way, musical lessons are enriched, while the students participate in a creative and emotional way in the educative process.

\section{Parameters of the Singing Activity}

When speaking of the usage of new technologies in the musical classes, the singing activity provides the best opportunities. It is a main musical activity. Due to its accessibility (immediate performance with voice) the students prefer it and sing with high motivation and emotionality. The specifics of the singing activity and the unity of the melody and the lyrics integrate it with poetry, while with the appropriately set by the pedagogue tasks, the activity could be paired also with dance. From here, the role of the audio-visual means is especially important. The creation of video clips to songs is arduous and requires certain conditions and preparation. The creation of musical accompaniment to the song repertoire with the help of a synthesizer, however, is a necessary skill of the pedagogue, which they have to develop and perfect.

There are pre-made accompaniments to songs (backing tracks), which are used successfully. Sometimes the teacher has to create such themselves. When perceiving music and getting to know a new work, it is good to sing the main theme, if it is vocally appropriate. Here, a musical accompaniment can also be applied. The skill of creating an accompaniment is used also when working with vocal groups and choirs. In this way, the diversity of singing activity helps for the creative expression of the students, while the accompaniment enriches the musical performance. If there is desire and interest, the musical pedagogue would overcome the challenge of the creation of accompaniment to a melody for the effective participation of the students in the artistic and creative activity.

\section{Creating Accompaniment to a Melody by Using a Synthesizer}

Modern computers and music recording software, as well as the synthesizer, provide opportunities for the creation of adequate accompaniments. For the musical pedagogue, the activity is markedly creative. Lately, the sound of the synthesizer has became an inevitable part of the modern musical environment. Its timbre and technical capabilities make it an "accomplice" with a creative purpose for a varied musical activity, as in the class in music and the audio recording studio, so in shows on the radio, television, cinema, theater and the stage podium.

On this keyboard computer musical instrument, it can be played with the timbres of different musical instruments separately and in combination, with the usage of different rhythms. A turning point in the perfection of the synthesizer is the transition of sound technology from analog to digital. In this way, the musical instrument is transformed into a computer and its capabilities are increased significantly. In order to master the capabilities of the new computer musical instruments and to achieve highly artistic results, not only musical skills are need, but also technical knowledge, a new type of thinking and imagination.

There are models, which fall into the group of "the master keyboards". These instruments are used mainly for studio work. They are equipped with a dynamic pianist keyboard, with the real number of octaves (as in the piano), but they lack a factory-made sound card with timbres. The sounds in them are produced through midi links to outside source sound cards.

The models of the class "Music Workstation" are predominantly designed for performance in real time. They are equipped with their own timbres, an option for quick change of the timbre, have a dynamic keyboard, and a feature for stacking and compiling different timbres and sounds.

During the 1980 's, the digitalization of sound led to the appearance of the MIDI technology and sound sampling. In 
this way, the problem of analyzing, processing and synthesizing sound from an outside source was solved. Synthesizers of this type provide the music teacher with an opportunity to present a certain song from the curriculum not only as a single-voice melody, but as a complete orchestra musical work. For that purpose, the teacher needs to understand several key parameters, concerning the relevant melody:

$=$ The melody has to be harmonized - letter markings need to be written under the note text. It has to be noted that in popular music these markings are slightly different.

- When the chord is major, it is written with the corresponding letter, with the exception of the note $\mathrm{Si}$, which in most western musical publications is marked by the letter $\mathrm{B}$, and not with the used in musical theory letter $\mathrm{H}$.

- A single letter with no other markings is read as a major triad, built on the given tone.

- When the chord is minor, invariably always, m (moll) has to be written, next to the letter designation, for example Dm.

- Alterations are always written with /\# or with b/, for example - C\#, and not with the known word designations.

- Abbreviations are also used, such as: dim- diminished, for a diminished chord.

- The used digit markings are only the following: 5, 7, 9, since most of the synthesizer models with an auto arranger and accompaniment do not recognize the more complex chords. The Arabic digits correspond to: 9 ninth, 7 - seventh, 6 - sixth, 5 - fifth.

- Often in the markings with digits, when a certain degree of the chord has to be raised or lowered, symbols, such as + and - are used. For example, 5- for a lowered fifth tone or $7+$ for a raised seventh tone, etc.

- Many times, chords, written as fractions, can be seen. In these cases, the "denominator" marks the specific tone in the bass, while the "numerator" - a specific chord, built over the bass. Such way of writing, when used for more complex chords, facilitates reading.
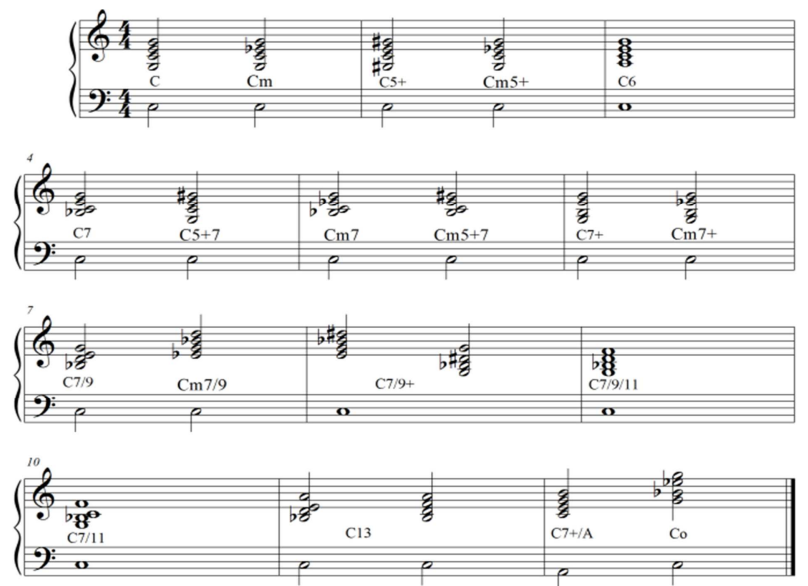

Figure 1. The most widely used chords in the musical accompaniment of children's songs in the music curriculum at school
$=$ Before choosing a specific variant of arrangement, it is necessary for the teacher to known the character, tempo and desired style, in which the song will be played. A given melody could sound equally good in several different styles.

$=$ The synthesizer gives opportunities for corrections of the tempo and the tonality. The correct assessment - changes to what degree are appropriate - is a question of the intelligence and professionalism on part of the teacher.

After the whole image of the musical work has been established in the mind or on a sheet, the teacher is done with their musical knowledge and it comes time for the technical and computer skills, needed for working with the synthesizer.

Each model of synthesizers offers a varied number of installed samples for automatic accompaniment. Some of the synthesizers, apart from the embedded (pre-programmed) samples, have the option of saving others, in designated for that purpose memory banks.

Each of the samples (arrangement) has strictly specified Intro (introduction) and Coda or Ending. They are from 2 to 8 bars and consist of short, complete musical phrases, which can be played in a major or a minor mode.

The synthesizer alone chooses the modal inclination, according to the last set (played) chord.

$=$ Intro - a predefined sample of several bars, in accordance to the modal inclination of the first chord, which is played, in order for the accompaniment sample to start.

= Coda or Ending - a predefined sample of several bars, in accordance to the modal inclination of the last chord, which is played at the end of the accompaniment.

$=$ Break - a sample with a length of 1 or 2 bars. They are pre-programmed musical phrases, or sounds of percussion instruments, along with sound effects, which are included during playing of the accompaniment and serve for a temporary change of the rhythm and the atmosphere of the repeating sample.

The automatic accompaniment at its core represents a continuous repetition of the chosen sample of accompaniment, whose harmonic functions are changed, according to the played by the teacher chords.

For seamless work with the automatic accompaniment, the teacher has to be well acquainted with the different for the individual models synthesizers and methods of accompaniment.

The most often found and most popular methods of accompaniment are:

ONE FINGER - it is possible to play 4 main types of chords

= when pressing a single key (the root note of the chord), a major triad is played.

= when two keys are pressed simultaneously (the root note of the chord and whichever key on its right), a minor triad is played.

- when pressing three keys simultaneously (the root note of the chord and two more keys, right from it), a major small four chord is played.

- when pressing four keys simultaneously (the root note of the chord and three more keys, right from it), a minor small 
four chord is played.

SINGLE FINGER - it is possible to perform 4 - main types of chords.

= when a single key is pressed (the root note of the chord), a major triad is played.

= when two keys are pressed simultaneously (the root note of the chord and whichever black key on its left), a minor triad is played.

$=$ when two keys are pressed simultaneously (the root note of the chord and whichever white key, left of it), a major minor tetrad is played.

$=$ when three keys are pressed simultaneously (the root note of the chord, and whichever white and black keys, left of it), a minor-minor tetrad is played.

CHORD INTELLIGENCE - allows playing the seven basic types of chords. This is the most often used and most popular method for auto accompaniment.

= when a single key is pressed (the root note of the chord), a major chord - major chord is played.

= when two keys are pressed simultaneously (the root note of the chord and another key, right from it - at an interval of a minor third), a minor chord is heard.

= when two keys are pressed simultaneously (the root note of the chord and another key, left of it - at an interval of a major second), a major chord 7 is heard.

$=$ when two keys are pressed simultaneously (the root note of the chord and another key, left of it - at an interval of a minor second), a major chord $7+$ is heard.

$=$ when three keys are pressed simultaneously (the root note of the chord and another key, left of it - standing at an interval of a major second, and another key, on its right standing at an interval of a minor third) a minor chord 7 is heard.

= when pressing three keys simultaneously (the root note of the chord and another key to its left - standing at an interval of a minor second and another key, on its right standing at an interval of a minor third) a minor chord $7+$ is heard.

Regardless of the octave location and the corresponding inversion of the chord, the synthesizer will use the same accompaniment.

FINGERED - in this system, chords with the standard chord fingering can be performed. This method allows the usage of much more types of chords, such as: diminished, augmented, and so on. The condition is that they have to be played with all their tones. This method recognizes about 15 types of chords.

It is needed to point out that no matter in which inversion a given chord is being played, the synthesizer always interprets it in a basic harmonic state.

An exception is when only a single key is pressed - in that case, most of the different models of synthesizers will play in major.

There are other methods of auto accompaniment, which use from 15 to 23 types of chords and their inversions.

Usage of a sequencer in the synthesizer is needed when we want to create a musical accompaniment to a given melody, while ignoring the auto accompaniment. This means that each tone of the musical accompaniment has to be composed, played and recorded in the memory of the synthesizer.

In general terms, the principle of work is the following:

At the beginning we set the needed meter and tempo. We arrange the needed for the accompaniment synthesized sounds in separate tracks, so that each timbre can be directed and controlled independently. The principle of arrangement: synthesized sound - track, is according to the General midi technology. The corresponding midi channels are set, as well as the controllers for changing the main parameters of the synthesized sound, the octave groups, all functions, related to the tone characteristics of the synthesized sound. Then, each part is played and recorded individually. This is done in separate short samples or "loops".
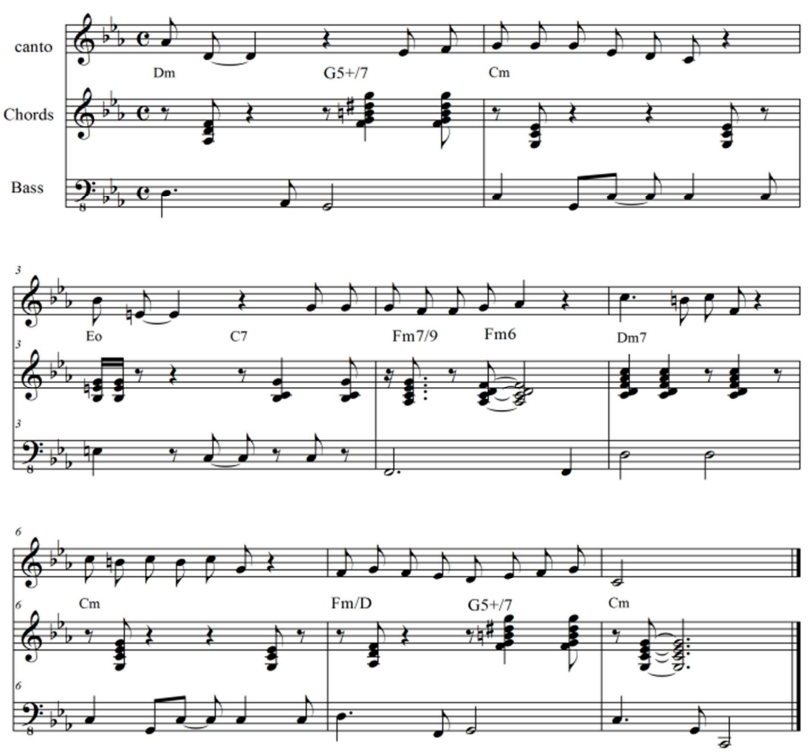

Figure 2. Song (music: Haigashod Agasian, song title: the Magic Words).

In the course of work, different functions are used, concerning the rhythmic alignment, dynamics, increase and slowing of the tempo. If multiple repetitions of a certain sample are needed, or the duplication of a specific line in another timbre, it is possible to copy and arrange, without the need of re-playing it. All this can be achieved also without the usage of the keyboard of the synthesizer, while recording tone by tone and setting the tone durations, dynamics and absolutely everything only by using the main buttons. This involves multiple computations.

It should always be started by recording first the percussion instruments and the bass part. When all musical lines have been played and recorded in the final order, it is time for balancing and mastering the separate tracks for achieving the desired sound of the end product.

Furthermore we have to underline that: the performed with an automatic accompaniment or with a sequencer musical works adopt the relevant genre-style orientation. The different accompaniments built differently the artistic image, giving it certain style and genre characteristics. The appropriately chosen automatic accompaniment for a given 
musical work has an important role in the artistic expression of the teacher.

With the purpose of establishing the pedagogic validity of the usage of author's accompaniments to songs and themes from musical works, provisioned for listening, during the school year of 2013-2014, a pedagogical experiment was performed with students of the 6th grade in the general school, of an age of 12-13 years.

Half of the songs, provisioned for performance, according to the curriculum, approved by the Ministry of Education and Science, and half of the themes of the works for listening, were played with especially prepared by the experimenter author's accompaniments. At the end of the school year, an ascertainment experiment was performed, including surveys, tests, etc. The students stated that the songs, performed with an especially prepared accompaniment, were more liked, interesting and expressive. A more important result was the following: the students performed with enthusiasm the songs, learned with the electronic accompaniment, while they had difficulties remembering some of the other songs. The students could start signing the themes of the musical works, learned with the accompaniment, often naming the title and the author, while the themes, studied without accompaniment, were vague in their minds, they could not remember them.

These eloquent facts proof unambiguously that:

\section{Results}

- The original accompaniments to songs and themes to musical works leave long-lasting trails in the minds of the performers.

- The enhanced musical images of the songs or the themes from musical works ease in the students into the musical art, help them get involved in the musical activities of performance and perception of music. When the main themes from a musical work, have been learned in advance with an accompaniment, this allows one to follow consciously the musical development in the work, with which it will invoke a much more strong emotional reaction in the listener.

- The intensive enrichment of the musical-auditory experience of the students with varied in emotional content and intonation style melodies allow for accelerated development of the musical hearing, which is a prerequisite for active participation in musical activities.

\section{Conclusion}

The synthesizer plays an important role among electronic musical instruments and provides new principles of sound production and new performance opportunities. Opportunities are provided for the music pedagogue to create accompaniment and to present the single-voice melody as a complete orchestra musical work.

\section{References}

[1] Becheva, Rositsa; Becheva, Maria. "Methodology of Learning the Synthesizer with Accompaniment Functions" - Lodos, Sofia, 2001 ( Бечева, Росица; Бечева, Мария. "Методика на обучението по синтезатор с акомпаниращи функции" Лодос, София 2001)

[2] Georgiev, Andrean. "Basics of Musical Computer Technologies" - Sofia University, Sofia, 2004. ( Георгиев, Андреан."Основи на музикалните компютърни технологии" - СУ, София, 2004 )

[3] Georgiev, Andrean. "Computer music"- Sofia 2005 ( Георгиев, Адриан. "Музика с компютър" София - 2005г. )

[4] Mincheva, Penka. "Musical Education in the General School". Publ. Prosveta, Sofia, 1994. ( Минчева, Пенка. "Музикалното възпитание в общообразователното училище" изд. Просвета, София, 1994 )

[5] Mincheva, Penka. Music and Intellect. Sofia, 1994 ( Минчева, Пенка. Музиката и интелектът. София, 1994 )

[6] Mincheva, Penka ; Pehlivanova,Petya; Hristova, S. "Music for the Fifth Grade". Sofia, 2006 ( Минчева, Пенка ; Пехливанова, Петя ; Христова, С. "Музика за пети клас". София 2006 )

[7] Naidenov, Ivan. "Synthesizer in music lessons at school" , Academy of Music, Dance and Fine Arts - Plovdiv 2009 (Найденов, Иван."Синтезатора в урока по музика в СОУ", изд. АМТИИ - Пловдив, 2009)

[8] Pehlivanov, Jean. "Music software for recording and editing the sound - a new tool which complements and improves the skills of modern music teachers at school". Academy of Music, Dance and Fine Arts - Plovdiv 2012 ( Пехливанов, Жан. "Музикален софтуер за запис и обработка на звука ново средство, допълващо и усъвършенстващо уменията на съвременния учител по музика в СОУ". изд. АМТИИ Пловдив 2012)

[9] Vahromeev, V. "Elementary music theory". Sofia 1963. ( Вахромеев, В. "Елементарна теория на музиката", София 1963)

[10] Hadjiev, P. "Elementary music theory". Sofia 1974. ( Хаджив, Парашкев. "Елементарна теория на музиката", София 1974 